\title{
A FORMAÇÃO PROFISSIONAL EM SAÚDE NA REDE FEDERAL DE EDUCAÇÃO PROFISSIONAL E TECNOLÓGICA
}

\author{
Mércia Maria de Santi Estácio; Edilene Rodrigues da Silva; Anna Katyanne Arruda \\ Silva e Souza; Ana Flavia de Souza Timoteo \\ Escola de Saúde da Universidade Federal do Rio Grande do Norte (ESUFRN)
}

DOI: $10.15628 /$ rbept.2018.7270

Artigo submetido em maio/2018 e aceito em junho/2018

\begin{abstract}
RESUMO
Trata-se de uma pesquisa qualitativa, norteada e estruturada a partir da análise documental, tomando como base documentos e publicações institucionais, assim como marcos legais da Educação Profissional e Tecnológica no Brasil, inclusive no que tange à normatização da formação inicial e continuada, de nível técnico e tecnológico em saúde. Versa sobre a história da formação profissional em saúde no âmbito da Rede Federal de Educação Profissional e Tecnológica (RFEPT), tendo como lócus de pesquisa a Escola de Saúde da Universidade Federal do Rio Grande do Norte (ESUFRN), uma Unidade Acadêmica especializada na formação profissional em saúde, regulamentada pela Resolução no 008/15-CONSUNI, de 22 de Maio de 2015. Este artigo objetiva descrever a experiência da qualificação e profissionalização de trabalhadores da área de saúde pela ESUFRN, através da oferta de cursos de formação inicial e continuada, técnicos, tecnológicos e de pós-graduação Lato e Stricto Sensu ao longo de sua trajetória histórica de 63 anos.
\end{abstract}

Palavras-Chave: Educação Profissional. Saúde. História. Rede Federal de Ensino.

\section{THE PROFESSIONAL HEALTH TRAINING IN THE FEDERAL NETWORK OF PROFESSIONAL AND TECHNOLOGICAL EDUCATION}

\begin{abstract}
It is a qualitative research, guided and structured from the documentary analysis, based on documents and institutional publications, as well as legal frameworks of Professional and Technological Education in Brazil, including with regard to the standardization of initial and continuing education, technical and technological level in health. It covers the history of professional training in health within the scope of the Federal Network of Professional and Technological Education (RFEPT). The research center is the School of Health of the Federal University of Rio Grande do Norte (ESUFRN), an Academic Unit specializing in training health professionals, regulated by Resolution No. 008/15-CONSUNI, dated May 22, 2015. This article aims to describe the experience of the qualification and professionalization of health workers by ESUFRN through the provision of initial and continuing training courses, technical, technological and postgraduate studies Lato and Stricto Sensu throughout its historical trajectory of 63 years.
\end{abstract}

Keywords: Professional Education. Health. History. Federal Education Network. 


\section{INTRODUÇÃO}

O Brasil vivenciou profundas mudanças com a Constituição de 1988, a Lei de Diretrizes e Bases LDB no 9193/1996 e o Sistema Único de Saúde. Nesse contexto e frente aos contínuos estudos e discussões sobre a educação profissional e tecnológica, a qual é regulamentada pelo Decreto no $5154 / 2004$ e posteriormente incorporada à LDB pela Lei 11.741/08, ocorreram alterações importantes na educação profissional e tecnológica (BRASIL, 2004, 2008; SILVA, 2015).

A educação profissional passa a ter organização própria, os planos de cursos passam a ser organizados baseados em competências, visando atender à atual divisão social e técnica do trabalho. $O$ mercado de trabalho exige então que o trabalhador tenha conhecimento para a vida produtiva, desenvolvendo competências e habilidades adaptáveis ao trabalho flexível, mais abrangente, atendendo às demandas de um mercado em constante mudança (BRASIL, 1999; PEREIRA; RAMOS, 2006; SILVA, 2015).

As instituições de formação em saúde têm desprendido esforços para acompanhar as discussões sobre o compromisso e os desafios da formação profissional em saúde e seus desdobramentos no Brasil, considerando a necessidade de prover a formação de um trabalhador mais apto para lidar com os problemas da sociedade brasileira (SILVA, 2015).

Este artigo versa sobre a história da formação profissional em saúde no âmbito da Rede Federal de Educação Profissional e Tecnológica (RFEPT), tendo como lócus de pesquisa a Escola de Saúde da Universidade Federal do Rio Grande do Norte (ESUFRN), uma Unidade Acadêmica especializada na formação profissional em saúde, regulamentada pela Resolução no 008/15-CONSUNI, de 22 de Maio de 2015, a qual compõe a Rede Federal de Educação Profissional, Científica e Tecnológica, estando filiada ao Conselho Nacional de Dirigentes das Escolas Técnicas Vinculadas às Universidades Federais (CONDETUF), e é também membro da Comissão de Integração entre os serviços de saúde e as instituições de ensino (CIES), na qual apoia a construção de planos regionais de educação permanente.

Esta escola vem atuando na formação profissional em saúde em diferentes níveis e modalidades de ensino norteada, pelas exigências legais, no contexto de mudanças ocorridas no mundo do trabalho e da educação e nos processos de trabalho em saúde e em enfermagem, buscando acompanhar o movimento das políticas públicas em que a sociedade exige um novo perfil de trabalhador na área de saúde. Por conseguinte, procura-se atender aos requisitos técnicos exigidos à força de trabalho, e, por outro, há o compromisso ético em formar profissionais com visão crítica, com conhecimento e capacidade de pensar e agir politicamente. 
Nos últimos anos, havendo a necessidade de estender a formação profissional no eixo tecnológico da saúde, os compromissos da ESUFRN têm ultrapassado os limites do campo da enfermagem. A instituição diversificou a oferta de cursos técnicos e iniciou uma expansão do ensino, pesquisa e extensão para os níveis tecnológicos e de pós-graduação. Esse trabalho tem proporcionado o seu desenvolvimento e o reconhecimento de suas atividades regulares. A escola vem participando de programas e processos de formação e de educação permanente junto ao Ministério da Educação e Ministério da Saúde, promovendo a qualificação de profissionais para o Sistema Único de Saúde (SUS). Dentre eles: Programa Nacional de Educação na Reforma Agrária (PRONERA), Projeto de Profissionalização dos Trabalhadores da Área de Enfermagem (PROFAE), Programa de Educação pelo Trabalho para a Saúde (PET-SAÚDE), Programa Nacional de Acesso ao Ensino Técnico e Emprego (PRONATEC) e Rede E-TEC Brasil, este último, para a oferta de cursos de Educação Profissional e Tecnológica a distância.

São oferecidos cursos de Educação Profissional dentre os quais: Mestrado Profissional em Saúde e Sociedade; Pós-Graduação Lato Sensu em Cuidados e Práticas Integrativas em Saúde; em Enfermagem ObstétricaRede Cegonha; Graduação Tecnológica em Gestão Hospitalar e Cursos Técnicos em Agente Comunitário de Saúde; Enfermagem; Estética; Gerência de Saúde; Massoterapia; Registros e Informações em Saúde; Vigilância em Saúde.

Dessa forma, o presente artigo tem por objetivo descrever a experiência da qualificação e profissionalização de trabalhadores da área de saúde pela ESUFRN, através da oferta de cursos de formação inicial e continuada, técnicos, tecnológicos e de pós-graduação Lato e Stricto Sensu ao longo de sua trajetória histórica de 63 anos na RFEPT.

\section{METODOLOGIA}

O presente estudo traz como metodologia, a pesquisa qualitativa, que será norteada e estruturada a partir da análise documental, tomando como base documentos e publicações institucionais, assim como marcos legais da Educação Profissional e Tecnológica no Brasil, inclusive no que tange à normatização da formação inicial e continuada, de nível técnico e tecnológico em saúde.

Para o aporte teórico utilizaram-se elementos conceituais de Freire (2004, 2011), estudos sobre a educação em enfermagem, a educação profissional e o mundo do trabalho em saúde e fontes documentais que regulamentam a Educação Brasileira.

Como marcos legais foram analisados documentos como as Diretrizes e Bases da Educação-Lei 9394/96 de 20 de dezembro de 2006, o Plano 
Nacional de Educação- Lei 13.005 de 20 de junho de 2014, o Parecer CNE/CEB no 16/99 de 05 de outubro de 1999 que trata das diretrizes curriculares nacionais para a educação profissional de nível técnico, os Referenciais curriculares nacionais da educação profissional de nível técnico para a área profissional saúde e a Resolução $n^{\circ} 6$, de 20 de setembro de 2012 que define as diretrizes curriculares nacionais para a educação profissional técnica de nível médio, entre outros.

A análise desses documentos suscitou as considerações de autores como Silva; Aquino e Germano (2006), Gomes, Liberalino e Silva (2006), Silva e Timóteo (2007), Silva, (2015) que tratam da formação profissional em saúde.

\section{A EVOLUÇÃo dA FORMAÇÃo PROFISSIONAL EM SAÚdE NO CONTEXTO DA UNIVERSIDADE FEDERAL DO RIO GRANDE DO NORTE}

\subsection{ESCOLAS DE AUXILIARES DE ENFERMAGEM DE NATAL DA UFRN}

A Escola de Auxiliares de Enfermagem de Natal (EAEN), instituição que iniciou o ensino profissional da enfermagem no Rio Grande do Norte, foi criada sob a Portaria Ministerial № 381, de 07 de dezembro de 1955, com objetivo de formar pessoal qualificado em enfermagem. Em 1964, foi incorporada à Universidade Federal do Rio Grande do Norte, inicialmente agregada à Faculdade de Medicina, conforme Resolução do CONSUNI no 02/64 (SILVA, 2003).

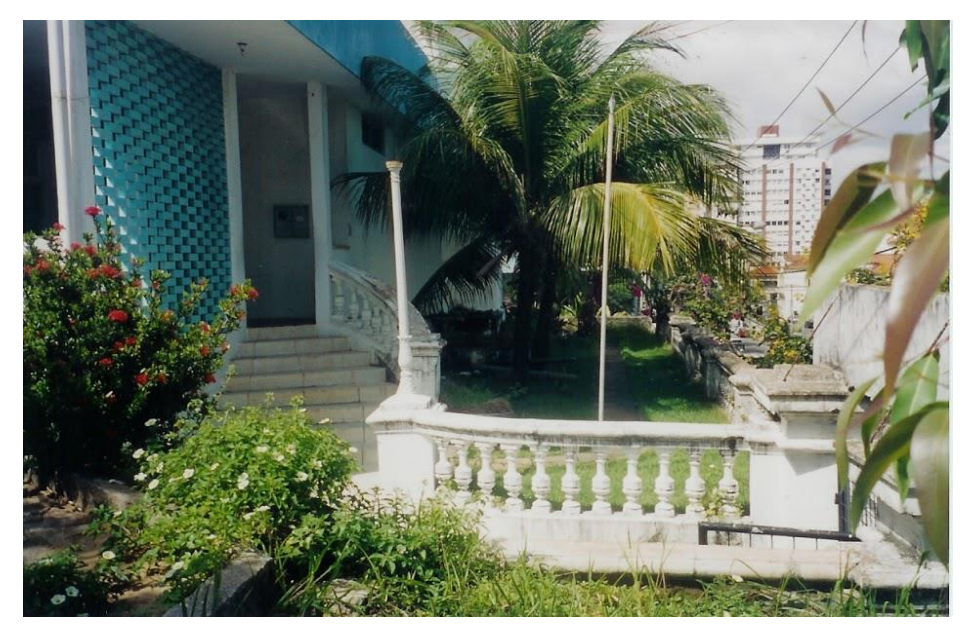

Figura 1: Entrada do prédio da antiga Escola de Auxiliares de Enfermagem de Natal, na avenida Nilo Peçanha. Natal, RN. 
A Escola de Auxiliares de Enfermagem de Natal teve de ceder a sua infraestrutura física (Figura 1) e de pessoal ao novo curso de graduação em enfermagem do Departamento de Enfermagem da UFRN, mudança ocorrida visando atender à reforma do ensino universitário em 1968 e de nível médio em 1971 (SILVA, AQUINO, GERMANO, 2006).

Desde então, a Escola de Auxiliares de Enfermagem de Natal seguia funcionando em meio às dificuldades. Continuou formando auxiliares e técnicos de enfermagem, na modalidade regular, na condição de cursos subordinados ao Departamento de Enfermagem e mantidos através de convênio celebrados, a partir de 1980, entre a Secretaria de Estado de Educação e Cultura e a UFRN. As condições de funcionamento da Escola eram precárias com restrito espaço físico, sem orçamento próprio e com quadro docente exclusivamente vinculado à Secretaria Estadual de Educação e Cultura (SEC) (SILVA, AQUINO, GERMANO, 2006; GOMES, LIBERALINO, SILVA, 2006).

Neste sentido, o processo de educar é concebido como um momento de troca e aprendizagem, mais do que um fenômeno espontâneo, torna-se uma condição que requer interação e intencionalidade, ou seja, a interação de quem almeja ser educado, o apoio de quem se propõe a colaborar com o sujeito em transformação, e o estabelecimento da interação mútua dos sujeitos do processo de aprendizagem (SILVA; TIMOTEO, 2007).

$\mathrm{Na}$ época, a EAEN qualificava trabalhadores de nível médio de enfermagem, com forte reconhecimento pela comunidade e mercado de trabalho, oferecendo duas formas de ingresso no curso de auxiliar de enfermagem: uma através da escola estadual conveniada, com duração de dois anos; e a outra através de curso intensivo, com duração de onze meses. Realizava seleção anual de candidatos, tendo como pré-requisito a conclusão do $1^{\circ}$ grau completo e aprovação no exame seletivo.

Em 1996, a EAEN filia-se ao CONDETUF e em 04 de setembro de 1997, a Escola de Auxiliares de Enfermagem de Natal foi reestruturada, conforme Resolução no 057/97 do Conselho de Administração (CONSAD), deixando de subordinar-se à estrutura do Departamento de Enfermagem, reavendo, assim, do ponto de vista político-administrativo, seu perfil institucional de órgão suplementar da UFRN, o que lhe assegurou autonomia financeira e pedagógica, bem como impulsionou a sua reorganização didática e administrativa.

Neste período o quadro docente era composto por 11 professores ${ }^{1}$ cedidos pela Secretaria Estadual de Educação. Entre 1998 e 1999, a Escola foi dirigida, por docentes vinculados ao Departamento de Enfermagem da

\footnotetext{
${ }^{1}$ Ana Maria Queiroga de Souza, Edilene Rodrigues da Silva, Francisca Idanésia da Silva, Gilvania Magda Luz de Aquino, Maria Goretti de O. Matias, Maria José Fernandes Torres, Maria Lúcia da Silva Lima, Maria Luzinete Dantas, Maria de Fátima Costa, Nilva Medeiros da Silva, Agripino Fernandes Filho.
} 
UFRN. Com a reestruturação da Escola de Auxiliares de Enfermagem de Natal/UFRN, foi determinada a realização do primeiro Concurso Público para o seu quadro docente.

As primeiras seis professoras efetivas da Escola assumiram em 1998, passando a integrar e fortalecer o quadro docente da Escola de Auxiliares de Enfermagem de Natal da UFRN (Figura 2).

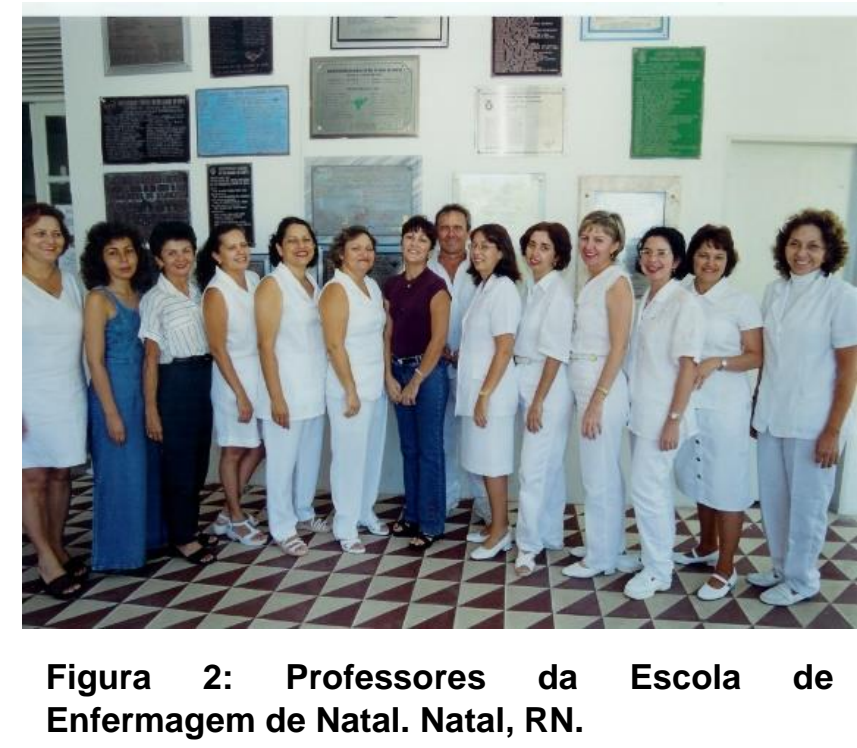

No período de 1999 a 2002 assumem a direção e a vice-direção da Escola, as professoras Cleide Oliveira Gomes e Rita de Cássia Girão. Objetivando atender a legislação vigente, houve atualização e reorganização dos planos de cursos técnicos na área da saúde a partir de orientações da Secretaria de Educação Profissional Técnica e Tecnológica (SETEC) do Ministério da Educação (MEC), da ABEn e do CONDETUF.

Essa nova fase ocorreu durante o período efervescente da história política da educação no país com a aprovação da Lei de Diretrizes e Bases da Educação Nacional - Lei oㅜ 9.394, de 20 de dezembro de 1996, influenciada pelo modelo neoliberal, o qual procura diminuir a interferência do Estado na sociedade, deixando que as chamadas leis do mercado regulassem as relações sociais.

\subsection{ESCOLA DE ENFERMAGEM DE NATAL DA UFRN}

$\mathrm{Na}$ perspectiva de atender à nova lei de Diretrizes e Bases da Educação, a Escola de Auxiliares de Enfermagem de Natal da UFRN passou a denominar-se Escola de Enfermagem de Natal (EEN) da UFRN, solicitação 
aprovada pela Resolução № 064/99, de 16 de dezembro de 1999, do Conselho de Administração - CONSAD.

A preocupação dos docentes da EEN com a qualidade da formação dos profissionais egressos dessa escola tem sido uma constante, e acentuouse com a necessidade de construção do novo currículo, a adequação à nova legislação da educação profissional brasileira e mudanças no processo educacional da formação do técnico em enfermagem, valorizando a construção do conhecimento pelo educando e o desenvolvimento de atitudes críticas e reflexivas.

É com este entendimento que Freire descreve que ensinar

\begin{abstract}
[...] não é transferir conteúdo a ninguém, assim como aprender não é memorizar o perfil do conteúdo transferido no discurso vertical do professor. Ensinar e aprender têm que ver com o esforço metodicamente crítico do professor de desvelar a compreensão de algo e com o empenho igualmente crítico do aluno de ir entrando como sujeito em aprendizagem, no processo de desvelamento que o professor ou professora deve deflagrar (FREIRE, 2004, p. 118-119).
\end{abstract}

$\mathrm{Na}$ Escola de Enfermagem, gradativamente os educadores foram substituindo as metodologias e as práticas educacionais tradicionais, que privilegiavam a transmissão, fragmentação, descontextualização, memorização e reprodução de conhecimento, e que contribuíam para uma formação alienada do aluno - por metodologias que adotam abordagens inovadoras. A Escola realizava sistematicamente reuniões pedagógicas, oficinas, buscando assessorar o docente nesta nova fase.

Para tanto, os docentes e discentes buscam construir competências, habilidades e saberes, a partir de situações problematizadas da produção e síntese do conhecimento, através da pesquisa e experiências vividas, preparando o aluno/trabalhador.

Neste contexto construímos um plano de curso técnico em enfermagem com 0 intuito de formar 0 profissional técnico em enfermagem/cidadão, numa concepção de educação por competências, preparando-o para o trabalho e para a vida. Vislumbra-se um profissional de enfermagem preparado para prestar um cuidado que atenda à integralidade da assistência à saúde, como um direito de cidadania do ser humano.

A proposta curricular do curso técnico em enfermagem da EEN é aprovada conforme Resolução no. 01/2001-EEN, de 31 de julho de 2001, e Portaria ministerial no 30/2000/MEC/SEMTEC, de 21/03/2000.

No ano de 2001 a Escola integrou-se como executora ao Projeto de Profissionalização dos Trabalhadores da Área de Enfermagem (PROFAE), com o subprojeto denominado "Por uma profissionalização cidadã", qualificando 510 trabalhadores da enfermagem em diversos municípios do RN e em 2004, 356 Técnicos em Enfermagem, numa perspectiva multidimensional que englobou as competências técnica e científica, mas 
também política, ética e humana na formação do profissional cidadão. Esse projeto corroborou com a política de formação de recursos humanos do Ministério da Saúde, em atendimento às demandas geradas pela implementação do Sistema Único de Saúde e às transformações do mundo do trabalho (BRASIL, 2002).

Em 26 de abril de 2003 foi inaugurado o Complexo de Enfermagem, constituído pela Escola de Enfermagem de Natal, Departamento de Enfermagem e Pós-graduação em Enfermagem da UFRN, resultado do recurso da venda do terreno situado na Avenida Nilo Peçanha, 620, no bairro de Petrópolis, local em que funcionavam a Escola de Enfermagem de Natal e o Departamento de Enfermagem da UFRN. Com o novo espaço físico tínhamos melhores condições ambientais, mas permanecíamos sem condições de ampliação de oferta de novas turmas e cursos para atender a demanda crescente de qualificação dos trabalhadores da Enfermagem.

Em 18 de fevereiro de 2004 foi inaugurado o Anexo da Escola de Enfermagem de Natal da UFRN, vindo somar ao espaço então existente laboratórios, auditório, almoxarifado, salas de coordenação de curso e banheiros, fortalecendo o desenvolvimento e expansão da Educação profissional na Instituição.

O corpo gestor da Escola enfrentou inúmeros desafios ao longo dos anos, mas através de uma gestão democrática e participativa, empenhada em obter êxito, sempre teve clareza da necessidade da Escola desenvolver ações de expansão e consolidação no ensino, pesquisa e extensão buscando assim o seu reconhecimento pela própria UFRN e fora dos seus muros. E consequentemente, seguir na luta para atingir os requisitos necessários para ser reconhecida como Unidade Acadêmica.

Ressaltamos que em 2005 a Escola ofertava regularmente apenas o curso Técnico em Enfermagem com 220 alunos matriculados, contava com um corpo docente formado por 12 profissionais efetivos (08 mestres e 04 especialistas), oito professores cedidos através do convênio SEC/UFRN e um servidor técnico-administrativo graduado.

Em 2005, ano do Jubileu de Ouro da Escola de Enfermagem de Natal, a Diretora Edilene Rodrigues da Silva, que assumiu o cargo em 2004 e até os dias atuais continua à frente da direção da Escola planejou e coordenou diversas ações apresentando a comunidade em geral a trajetória histórica da EEN (Figuras 3 e 4). 




Figura 3: Placa comemorativa dos 50 anos da EEN. Natal, RN. 2005.

No período de 2006 a 2010, em parceria com Movimento dos Trabalhadores Rurais Sem Terra (MST) do RN, a Escola participou do Projeto de Formação Técnico-Profissional: Curso Técnico em Enfermagem concomitante com o Ensino Médio em áreas de Reforma Agrária do RN, que teve como objetivo geral promover a formação profissional de Técnico em Enfermagem integrado ao ensino médio dentro dos princípios éticos, políticos, humanísticos, visando atender as demandas da comunidade de assentados em áreas de reforma agrária, com uma concepção de saúde como um direito do cidadão.

Do total de 42 alunos matriculados, 34 colaram grau, foram beneficiados 16 assentamentos da reforma agrária, abrangendo diretamente 12 municípios, dentre outras localidades do Estado do Rio Grande do Norte.

A partir de 2007, em virtude das políticas de educação e saúde e da evolução do cuidado à saúde, bem como das políticas de inclusão social e da expansão profissional, a Escola passou a diversificar a oferta de cursos de forma a contribuir com a formação de outros profissionais da área de saúde. Ofertando o Curso de Graduação Tecnológica em Gestão Hospitalar para servidores da Universidade, por intermédio do Programa de qualificação e educação profissional da Pró-Reitoria de Recursos Humanos da UFRN, como forma de contribuir com a formação dos trabalhadores desta Universidade. Este curso passou a ser ofertado regularmente através do Sistema de Seleção Unificada - SISU.

Mediante estudos de demanda, em 2009, a Escola expandindo suas atividades passou a oferecer novos cursos como o Técnico em Registros e Informações em Saúde e Especialização Técnica em Enfermagem do Trabalho e em UTI.

Desde 2011, até o presente momento, a Escola de Saúde vem participando do Programa Nacional de Acesso ao Ensino Técnico e Emprego (PRONATEC), oferecendo cursos de qualificação profissional para 
estudantes do ensino médio da rede pública e beneficiários dos programas federais de transferência de renda e grupos em situação de vulnerabilidade social, inclusive da Educação de Jovens e Adultos através da oferta de cursos técnicos com duração média de um ano e meio e de cursos de Formação Inicial e Continuada (FIC), com carga horária variando entre 160 e 400 horas.

Vem se configurando como uma experiência exitosa que já possibilitou o resgate da autoestima e da cidadania, inserção no mercado de trabalho e inclusão sócio-educativa de cerca de 4808 alunos em 37 cursos de Formação Inicial e Continuada e 342 egressos de cursos técnicos nos 08 cursos Técnicos ofertados através da Bolsa-Formação nos municípios do RN.

Dessa forma, a EEN reafirmou sua concepção visionária, uma vez que ao longo dos anos sempre tem se mantido à frente das principais diretrizes e políticas da formação profissional em saúde, contribuindo para o fortalecimento do SUS, bem como primando pela qualidade da formação e pela construção de habilidades e competências indispensáveis aos profissionais que atuam na área da saúde.

Porém, apesar de todo o empenho, a Escola de Enfermagem de Natal ainda permanecia indefinida legalmente na UFRN, e sem o seu reconhecimento tornava-se cada vez mais difícil prosseguir com os projetos de expansão da instituição. No ano de 2013 houve ampliação do espaço físico da Escola e iniciou-se a tramitação do processo de criação da Escola de Saúde da Universidade Federal do Rio Grande do Norte (ESUFRN) Unidade Acadêmica Especializada em Educação Profissional em Saúde, bem como do seu Regimento Interno.

Foram muitos anos de luta desde a reestruturação da Escola de Auxiliares de Enfermagem de Natal, com momentos de embates, decepções, tristeza, fortalecimentos, retomadas, superação, crescimento, conquistas e tantos outros sentimentos envolvidos em uma trajetória fruto da construção coletiva dos docentes, estudantes, técnicos-administrativos, bolsistas e servidores terceirizados.

\subsection{ESCOLA DE SAÚDE DA UFRN}

Em 2015, a Escola de Saúde da UFRN (ESUFRN) é reconhecida como Unidade Acadêmica regulamentada pela Resolução no 008/15-CONSUNI, de 22 de maio de 2015, que tem como "finalidade desenvolver e aplicar conhecimentos de educação profissional na área da saúde em níveis de formação inicial e continuada, técnico, graduação e pós-graduação" (UNIVERSIDADE FEDERAL DO RIO GRANDE DO NORTE, 2018). 
Neste período, a Instituição continua destacando-se pela qualidade da formação e pela construção de habilidades e competências indispensáveis aos profissionais que atuam na área da saúde.

A partir do ano de 2017, a Escola também passou a ofertar cursos através do MedioTec EaD, uma iniciativa da Rede e-Tec Brasil destinado aos alunos regularmente matriculados no Ensino Médio das redes públicas de educação, socialmente vulneráveis, buscando ampliar as possibilidades de inserção profissional dos jovens quando da conclusão da etapa regular da educação básica.

No período compreendido entre os anos de 2004 até os dias atuais, vislumbrou-se o gradativo crescimento e desenvolvimento da Instituição no que se refere a aspectos quantitativos e qualitativos graças à adoção pelo corpo gestor de uma concepção de gestão democrática, baseada nos princípios da liberdade, participação, co-responsabilidade e tomada de decisões coletivas em relação às dimensões pedagógicas, administrativas e financeiras, a partir da socialização da missão institucional.

Portanto, a Escola a partir de 2007 diversificou qualitativamente e quantitativamente, a oferta de cursos de formação profissional, no eixo tecnológico ambiente e saúde, passou a oferecer um leque de cursos em diferentes níveis e modelos de oferta, como podemos observar no Gráfico 1. $O$ ingresso nos cursos técnicos ocorre por meio de processo seletivo anual, mediante Edital, e em consonância com a lei de cotas.

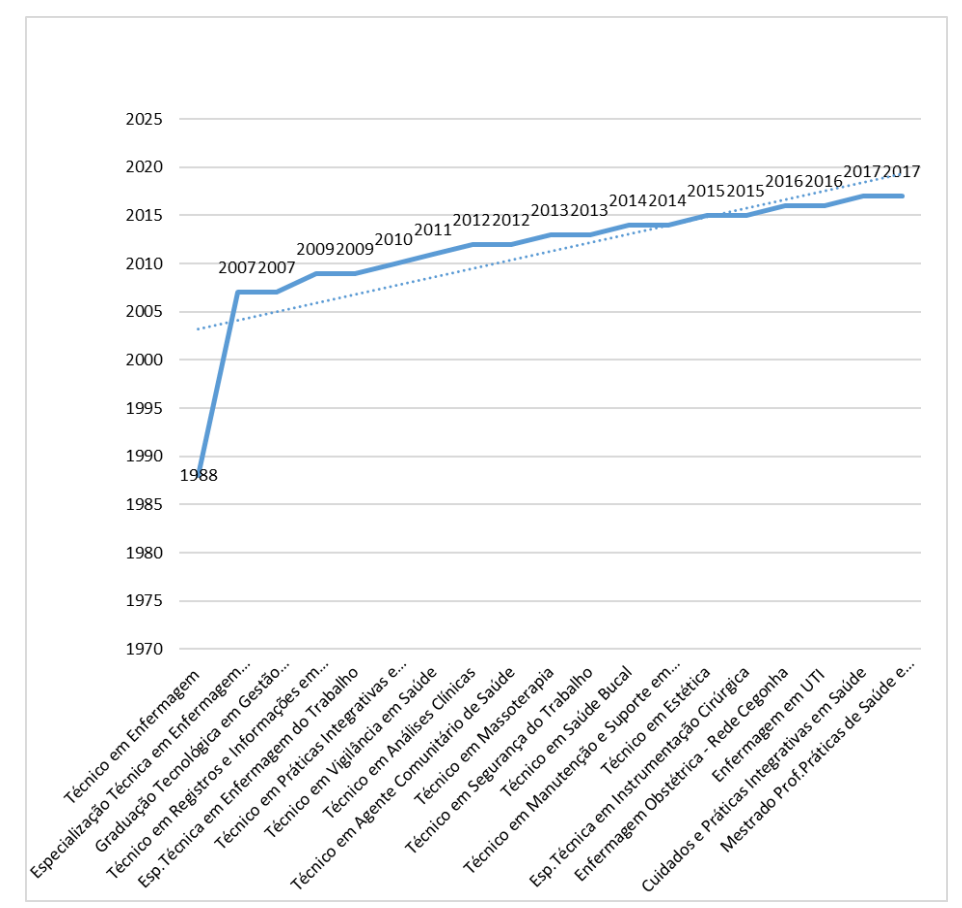

Gráfico 1: Demonstrativo dos cursos ofertados pela Escola de Saúde da UFRN, de acordo com ano de início, Natal, 2018. 
Em 2016, após ampla discussão interna, a ESUFRN submeteu à Coordenação de Aperfeiçoamento de Pessoal de Nível Superior o Projeto de Mestrado profissional em Práticas de Saúde e Educação que teve início em maio de 2017 com 15 alunos matriculados, após aprovação pela CAPES com área de concentração em Saberes e Práticas em Saúde e Educação e duas linhas de pesquisa: 1) Epidemiologia, vigilâncias e o cuidado em Saúde; 2 Saberes e práticas de gestão em saúde e educação.

O curso no formato de Mestrado Profissional vem agregar valor tanto à histórica trajetória da Escola de Saúde da UFRN na qualificação de profissionais da área de saúde e enfermagem, como também, enfatizar a parceria entre a UFRN e os gestores e trabalhadores do SUS no cenário local e nacional, o que por sua vez, contribui para o fomento e/ou fortalecimento do intercâmbio entre redes de formação e redes de atenção à saúde.

\subsection{CORPO DOCENTE E TÉCNICO-ADMINISTRATIVO RESPONSÁVEL PELA FORMAÇÃO PROFISSIONAL EM SAÚDE DA UFRN}

Com a expansão e fortalecimento da Rede Federal de Educação Profissional, Cientifica e Tecnológica realizada a partir de 2003 através das políticas do Governo Federal de Lula e Dilma (Presidentes do Brasil no período de 2003-2011 e 2011-2016, respectivamente) foi possível ampliarmos em mais de duas vezes o quantitativo de docentes, ou seja, em 2004 tínhamos 11 professores no quadro docente efetivo, com a ampliação ao longo dos anos passamos a contar com 40 docentes como observamos nos Gráficos 2 e 3.

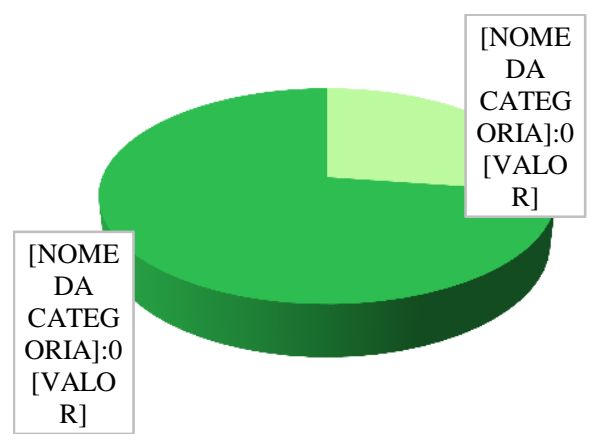

Gráfico 2: Demonstrativo da quantidade de docentes da Escola de Saúde da UFRN, de acordo com a qualificação no ano de 2004, Natal, 2018.

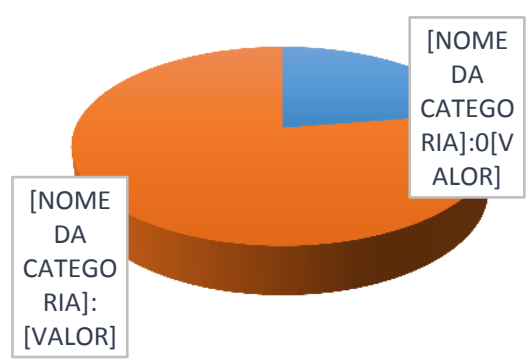

Gráfico 3: Demonstrativo da quantidade de docentes da Escola de Saúde da UFRN, de acordo com a qualificação no ano de 2017. 
Os docentes da Escola atuam, também, de forma destacada, em ações de extensão e pesquisa, participando e coordenando projetos estratégicos no campo da saúde, Educação Profissional, gestão, epidemiologia e corporeidade, atendendo às políticas de Educação Profissional da Secretaria de Educação Profissional e Tecnológica (SETEC) do Ministério da Educação e da Saúde.

No Gráfico 2 e 3 é possível depreender que no ano de 2004 o corpo docente era constituído por especialistas e mestres. Este cenário se modifica completamente tanto pela ampliação do número de docentes como pela sua qualificação, em 2017 a ESUFRN conta com 31 doutores e 9 mestres.

Os Servidores Técnicos administrativos também recebem nosso apoio e seguem se qualificando. Em 2004, a Escola contava com apenas um servidor efetivo, com graduação. Atualmente, o quadro de técnicosadministrativo é composto por 11 profissionais, sendo eles assistentes administrativos, técnicos em assuntos educacionais, secretário executivo, enfermeiros, bibliotecário-documentalista e técnico em tecnologia da informação, com qualificação, como podemos observar no Gráfico 4.

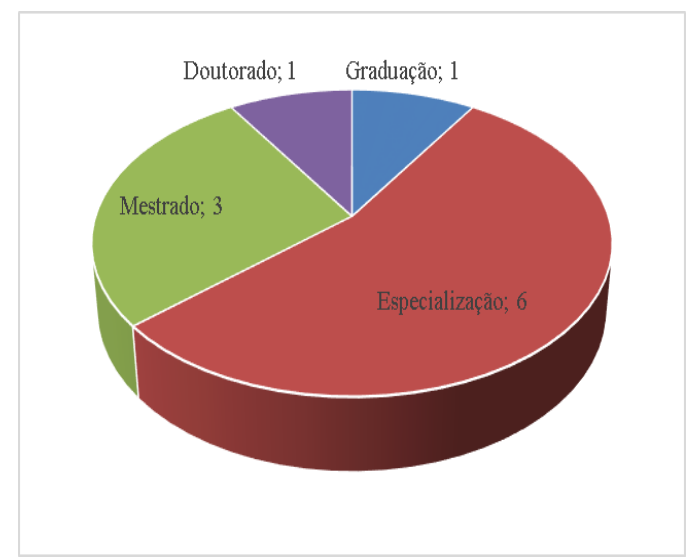

Gráfico 4: Demonstrativo da quantidade de TécnicosAdministrativo da Escola de Saúde da UFRN, de acordo com a qualificação no ano de 2017, Natal, 2018.

Desde 2004 até os dias atuais observamos a procura dos docentes por qualificação, os quais recebem apoio e incentivo da gestão. Planejamos a qualificação docente, nos organizando coletivamente visando atender a todos. 


\section{CONCLUSÃO}

A formação profissional em saúde mobiliza diversas competências que precisam ser construídas pelo egresso, integralizando os conhecimentos para cuidar profissionalmente no SUS, de forma humana e ética, comprometido com a vida e com o outro. Nesse sentido, é preciso pensar em estratégias pedagógicas para essa formação, que envolva metodologias de ensino que focalizem aprendizagem tanto dos procedimentos técnicos como 0 desenvolvimento da consciência crítica, corpo docente e técnicoadministrativo capacitado para lidar com as especificidades e enfrentar os desafios inerentes ao processo ensino-aprendizagem e execução dos cursos em diferentes níveis e modalidades. (SILVA, 2015)

Dentre tantas ações e estratégias, a ESUFRN vem realizando uma gradativa reestruturação da proposta curricular dos cursos técnicos oferecidos pela Instituição, de modo a focalizar a formação de um egresso com conhecimentos e habilidades para lidar com as constantes mudanças do mundo do trabalho, da saúde e da educação. Assumindo assim o compromisso com a formação de um profissional cidadão para exercer suas funções e compreender o contexto e a concepção de saúde tendo como referência princípios do Sistema Único de Saúde (SUS).

$\mathrm{Na}$ formação profissional, o processo de aprendizagem é organizado objetivando levar o estudante a apropriar-se de conhecimentos teóricos e práticos, desenvolver habilidades e competências de uma profissão. Freire concebe a formação para o trabalho numa perspectiva ampliada, numa relação permanente entre educação, trabalho e sociedade, possibilitando formar trabalhadores como cidadãos críticos, humanos, sociais e politicamente ativos. Então, neste processo de formação, o educando e o educador, sujeitos no mesmo ato, no processo de ensinar-aprender, independente da modalidade de ensino, são seres de diálogo, reflexivos, inacabados, inconclusos, conscientes de sua inconclusão, críticos, criativos, levando-os neste processo a aprenderem juntos (FREIRE, 2011; SILVA, 2015).

Dessa forma, a Escola fundamenta o perfil de conclusão dos cursos nestes princípios, concebendo o egresso do curso como um ser profissional, ser de práxis, educando/ trabalhador, sujeito ativo no seu trabalho, comprometido com a sociedade e com os homens, que atua dialogando permanentemente com o outro, capaz de refletir sobre seu fazer, seu saber e sobre ele mesmo.

Ao longo de sua evolução histórica, a Escola buscou através do crescimento e desenvolvimento quantitativo e qualitativo nos âmbitos didático-pedagógico, estrutural, organizacional e do seu quadro docente e técnico-administrativo a melhoria da formação humana em saúde desde a qualificação inicial e continuada à pós-graduação, ampliando e diversificando 
a oferta de cursos e atualizando o perfil profissional do egresso em seus diferentes níveis, de modo a favorecer o pensamento crítico acerca de seu processo de trabalho, desempenhando sua função de forma ética e de qualidade.

\section{REFERÊNCIAS}

BRASIL. Ministério da Educação. Educação Profissional: referenciais curriculares nacionais da educação Professional de nível técnico. Área Profissional: Saúde. Brasília: MEC, 2000.

BRASIL. Secretaria de Educação Média e Tecnológica. Educação Profissional: legislação básica. 5.ed. Brasília, jan. 2001.

BRASIL. Decreto no 5.154 de 23 de julho de 2004. Regulamenta o $\S 2^{\circ}$ do art. 36 e os arts. 39 a 41 da Lei no 9.394, de 20 de dezembro de 1996, que estabelece as diretrizes e bases da educação nacional, e dá outras providências. Brasília; 2004. Disponível em: http://www.planalto.gov.br/ccivil_03/_Ato2004-2006/2004/Decreto/D5154.htm. Acesso em 2013 maio. 28.

BRASIL. Lei no 11.741, de 16 de julho de 2008. Altera dispositivos da Lei $n$ o 9.394, de 20 de dezembro de 1996, que estabelece as diretrizes e bases da educação nacional. Brasília; 2008. Disponível em: https://www.planalto.gov.br/ccivil_03/_ato2007-2010/2008/lei/l11741.htm.

Acesso em 2013 maio. 28.

BRASIL. Conselho Nacional de Educação. Parecer CNE/CEB nํ 16/99 de 05 de outubro de 1999. Trata das diretrizes curriculares nacionais para a educação profissional de Nível Técnico. Brasília; 1999. Disponível em: http://portal.mec.gov.br/cne/arquivos/pdf/1999/pceb016_99.pdf. Acesso em 2013 maio. 28

FREIRE, P. Pedagogia do oprimido. 29. ed. Rio de Janeiro: Paz e Terra; 2011.

FREIRE, P. Pedagogia da esperança: um reencontro com a pedagogia do oprimido. 17. ed. São Paulo: Paz e Terra; 2011.

FREIRE, P. Educação e mudança. 13. ed. Rio de Janeiro: Paz e Terra; 2011.

FREIRE, P. Pedagogia da autonomia: saberes necessários à prática educativa. 29. ed. São Paulo: Paz e Terra; 2004.

GOMES, C. O; LIBERALINO, F. N; SILVA, F. I. A Construção de uma nova fase: Escola de Auxiliares de Enfermagem de Natal. In: Do Sonho à Realidade 50 Anos da Escola de Enfermagem de Natal. Natal: EDUFRN, 2006, p. 37- 49. 
SILVA, E. R. O Egresso do Curso Técnico em Enfermagem: formação profissional e a inserção no mundo do trabalho. 2015. 221f. Tese. (Doutorado) - Centro de Ciências da Saúde. Universidade Federal de Santa Catarina, Florianópolis, 2015.

SILVA, E. R.; AQUINO, G. M. L. de; GERMANO, R. M. A Escola de Auxiliares de Enfermagem de Natal Crises e desafios. In: Do Sonho à Realidade: 50 Anos da Escola de Enfermagem de Natal. Natal: EDUFRN, 2006, p. 4-90.

SILVA, E. R.; TIMOTEO, R. P. S. Profissionalização cidadã: mudanças na formação do trabalho de enfermagem. In: (Org.). Educando e produzindo conhecimento em enfermagem. Natal: EDUFRN, 2007.

UNIVERSIDADE FEDERAL DO RIO GRANDE DO NORTE (UFRN). Escola de Saúde (ES). Disponível em: < http://escoladesaude.ufrn.br/>. Acesso em: 02 jan. 2018. 